\section{Frequency of Dust-storms in the Egyptian Desert}

When I reviewed ${ }^{1}$ the book by Lieut.-Colonel R. A. Bagnold on the "Physics of Desert Sands and Dunes", I noted a statement by the author that dust-storms, as distinct from sand-storms, were of comparatively rare occurrence in the Egyptian desert, whereas duststorms were being reported in the news as interfering with the fighting in the Middle East every few days. At the time, I regarded the term 'dust-storm' as being somewhat loosely applied by the reporters, and to include sand-storms, but I have recently had the opportunity of reading a paper ${ }^{2}$ by Prof. F. W. Oliver which throws new light on this point. Prof. Oliver has lived since 1935 at Burg-el-Arab, thirty miles west of Alexandria, and he states that changes have occurred in recent times. The average duststorm frequency from 1935 to 1939 was 5 a year over the period January to May; in the same period of 1940 there were 8 , and in 1941 there were 32 storms. The total number for the year 1941 was 54, and in addition to the increased frequency, the severity was much greater.

Prof. Oliver accounts for this increased frequency first by the surface disturbance caused by war operations in the desert, such as construction of fortifications and movement of lorries; and secondly, by the removal of cover, that is, desert scrub, which was destroyed by the Bedouins when they evacuated from the district. $\mathrm{He}$ considers that extensive measures will need to be taken after the War to abolish the dust nuisance in these districts.

H. HeYwood.

Imperial College of Science and Technology,

$$
\text { S.W.7. }
$$

${ }^{1}$ NatURe, 48, 480 (1941).

2 "Some Remarks on Desert Dust-Storms". By F. W. Oliver. Pp. 16. (Alexandria: Whitehead Morris (Egypt), Ltd., 1942.)

\section{Social Reporting}

IN the review of Mass-Observation's recent report "People in Production"1, the main theme of this report seems to have escaped the reviewer's attention.

What "People in Production", a report on six months study in war factories, analyses out is a fundamental psychological tendency of our present civilization, seldom realized or studied-the 'quantitative approach'. The idea that you are doing well by producing a lot of things, by having so many tanks brought off the production lines every day; so many Flying Fortresses flown across the Atlantic every week; such and such an enormous percentage of men conscripted into the Forces, and of women directed into industry ; long hours of work ; impressive figures of war money expenditure-these have been the common encouragements of Lord Beaverbrook, Mr. Lyttelton, Mr. Bevin and others. Our production study attempted to show how this heavily quantitative approach has led to a neglect of qualitative considerations. These qualitative considerations are of two main types - the quality of the materials produced, and the quality of the personnel dealing with the product. The former type lies outside the realm of sociology, but no one who has read Hansard on the two days of the recent Censure Debate, including Mr. Lyttelton's speech, can doubt that there has been some muddled thinking on this side. We were concerned with the latter type.
We found over and over again that the qualitative, social and psychological factors were being ignored. The underlying assumption in war industry and in the Services, all the way through, is that men and women are units of subsidiary importance to machines, yet with many mechanical attributes. The qualitative human factors; which distinguish a soldier from a rifle, a working girl from a capstan lathe, are ignored to a surprising extent. This leads to many avoidable inadequacies. To put it in its simplest form : it does not matter how many tanks you have in Libya, or even how good they are, if the people handling them are not fully tank-minded, tank-educated, and tankdetermined. Lots and lots of everything will not win anything. 'It is the human element, both in producing and in using the products which will determine the outcome of the War. This elementary point has been astonishingly ignored. It is not so astonishing, however, if it is related to the growth of industry, with its economic and numerical incentives, and this, too, we have tried to trace out in "The People in Production". The statistical obsession of the social sciences has also contributed to a neglect of the real, human factors.

Such material is certainly topical, and as such might, I suppose, be called 'social reporting'. But even the social sciences cannot stand above the battle. With complacency, the reviewer concludes that our study shows how "countless relatively small mistakes are being made everywhere, an ordinary state of human affairs". We cannot, at present, afford to be ordinary. The "countless relatively small mistakes" are related to a central theme, which requires analysis. What a negation of sociology to dismiss it as merely an ordinary human state: what is social science about if not that? I for one am happy to be called superficial if in being so I am helping to illuminate the mentality of the present and to preserve the integrity of the future, however inadequately.

Mass Observation,

TOM Harrisson.

82, Ladbroke Road, London, W.11.

1 NATURE, 149, 711 (1942).

The review to which Mr. Harrisson objects made it abundantly clear that the report was concerned with "the quality of the personnel dealing with the product". Ten topics of the report were mentioned, all of which dealt with qualitative, social and psychological factors. The comment was made "Emerging from the survey of most of these problems is the evident need for everybody to understand more fully what other people are doing and the conditions of their work. The Fighting Services, the Supply Ministries, management, foremen and workers all need to know more about each other. Extensive reporting of the kind offered here is one means of fulfilling the need."

What Mr. Harrisson misunderstood as my complacency about the "ordinary state of human affairs" might better have been called pessimism, except that I believe it to apply to the state of enemy affairs as well as our own. To say that the small mistakes are related to a central theme is either a truism (since everything which happens in a social group is related to some vague central theme), or else it implies a dubious political or sociological dogma, as I supposed from Mr. Harrisson's remark, "Something is serjously wrong somewhere".
The Reviewer. 